\title{
Selection of prosthetic aortic valve and root replacement in patients younger than age 30 years
}

\author{
Rita Karianna Milewski, MD, PhD, Andreas Habertheuer, MD, PhD, Joseph E. Bavaria, MD, \\ Stephanie Fuller, MD, Nimesh D. Desai, MD, PhD, Wilson Y. Szeto, MD, Varun Korutla, and \\ Prashanth Vallabhajosyula, MD, MS
}

\begin{abstract}
Objective: Long-term outcomes of prosthetic aortic valve/root replacement in patients aged 30 years or younger are not well understood. We report our single institutional experience in this young cohort.
\end{abstract}

Methods: From 1998 to 2016,99 patients (age range, $16-30$ years) underwent
aortic valve replacement $(\mathrm{n}=57)$, aortic valve replacement and supracoronary
ascending aorta replacement $(\mathrm{n}=6)$, or aortic root replacement $(\mathrm{n}=36)$. A pro-
spectively maintained aortic valve database was retrospectively reviewed to com-
plete longitudinal functional and clinical data. Total follow-up was 493 patient
years.

Results: Surgical indications included primary stenosis/insufficiency $(52 \%$ $[\mathrm{n}=51])$, Marfan syndrome $(10 \%[\mathrm{n}=10])$, and endocarditis $(33.3 \%$ $[n=33])$. Fifty-eight patients $(59 \%)$ underwent mechanical valve replacement, with 41 patients $(41 \%)$ receiving a biologic/bioprosthetic valve. Twenty-five patients underwent aortic valve reoperation after index procedure with following indications: prosthesis-patient mismatch $1.0 \%(\mathrm{n}=1)$, prosthetic valve degeneration/dysfunction $10 \%(n=10)$, connective tissue $2 \%(n=2)$, and endocarditis $12 \%(\mathrm{n}=12)$. Mortality (30-day/in-hospital) and stroke rate were $3.0 \%$ $(\mathrm{n}=3)$ and $1 \%(\mathrm{n}=1)$, respectively. One-, 5-, and 10-year actuarial freedom from aortic valve reoperation by valve type was $89.1 \%, 84.6 \%$, and $69.4 \%$ for the Mechanical Valve group and 89.6\%, 70.9\%, and 57.6\% for the Biologic/Bioprosthetic Valve group, respectively ( $\log$ rank $P=.279$ ). Replacement valve size $\leq 21 \mathrm{~mm}$ was a significant risk factor for reoperation, and was associated with progression of mean aortic valve transvalvular gradients over follow-up. Valve type had no effect.

Conclusions: The choice of mechanical versus biologic/bioprosthetic valve does not affect freedom from reoperation or survival rates in this young cohort during mid- to long-term follow-up. Smaller aortic valve replacement size $(\leq 21 \mathrm{~mm})$ is a significant risk factor for reoperation and progression of mean aortic valve gradients. (J Thorac Cardiovasc Surg 2019;157:714-25)

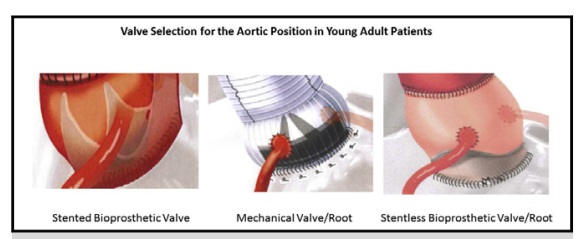

Prosthetic aortic valves for young adult patients (aged 30 years or younger).

\section{Central Message}

In patients aged 30 years or younger undergoing aortic valve replacement, prosthetic valve size rather than type influences mid- to longterm risk of reoperation.

\section{Perspective}

In young patients (aged 30 years or younger) requiring aortic valve replacement, there is a paucity of data on long-term comparative outcomes of mechanical versus biologic/bioprosthetic valves. Over follow-up of 493 patient years, we found valve choice did not affect patient survival or valve durability. Aortic valve size is identified as a significant risk factor for reoperation and progression of mean valve gradients.

See Editorial Commentary page 726.
From the Department of Surgery, Hospital of the University of Pennsylvania, Philadelphia, Pa.

Drs Milewski and Habertheuer contributed equally to this article.

Read at the 97th Annual Meeting of The American Association for Thoracic Surgery, Boston, Massachusetts, April 29-May 3, 2017.

Received for publication May 9, 2017; revisions received May 22, 2018; accepted for publication June 11, 2018.

Address for reprints: Prashanth Vallabhajosyula, MD, MS, Department of Surgery, Hospital of the University of Pennsylvania, 3400 Spruce St, Philadelphia, PA 19104 (E-mail: Prashanth.vallabhajosyula@uphs.upenn.edu). $0022-5223 / \$ 36.00$

Copyright $₫ 2018$ Published by Elsevier Inc. on behalf of The American Association for Thoracic Surgery

https://doi.org/10.1016/j.jtcvs.2018.06.102
Surgical treatment of aortic valve disease in pediatric and young adult patients is a complex decision process with no consensus regarding the optimal surgical procedure. Although primary valve repair or replacement with pulmonary autograft are well-established options, long-term

Scanning this QR code will take you to the article title page to access supplementary information.

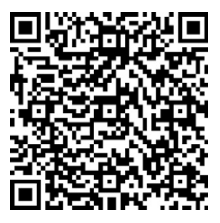




\section{Abbreviations and Acronyms \\ $\mathrm{ARR}=$ aortic root replacement \\ $\mathrm{AVR}=$ aortic valve replacement \\ $\mathrm{BAV}=$ bicuspid aortic valve \\ PPM $=$ prosthesis-patient mismatch \\ SHR $=$ subdistribution hazard ratio \\ $\mathrm{TAV}=$ tricuspid aortic valve}

outcomes in young patients undergoing prosthetic aortic valve/root replacement are not well studied. In young children, the Ross procedure is associated with significantly lower immediate and late mortality, and lower long-term complication rates compared with prosthetic valves. ${ }^{1}$ In pediatric populations, somatic growth and accelerated degeneration of bioprosthetic aortic valves leading to prosthesis-patient mismatch (PPM) have been a primary consideration. However, in young adults, somatic growth concerns no longer exit. Instead, valve choice is often driven by the considerations of left ventricular function, lifestyle, occupation, future pregnancy, requirement for anticoagulation therapy, and need for reoperation.

In young adult patients, surgical management of aortic valve disease is a lifelong process. A major concern of the Ross procedure in this patient population is that a single aortic valve disease requires double valve replacement. ${ }^{1}$ For young adults with preserved aortic cusp integrity with or without aortopathy, aortic valve repair or valve-sparing root reimplantation has presented as a viable alternative to prosthetic valve replacement. ${ }^{2}$ If the aortic valve cannot be preserved, either mechanical, stented bioprosthetic, or stentless biologic/bioprosthetic aortic valve replacement remains the procedure of choice, but often with recognized suboptimal mid- to long-term outcomes. ${ }^{1}$ The absence of an ideal definitive treatment option in this patient population requires an informed decision between patient and surgeon, and a meticulous assessment of surgical risk versus benefit that includes lifestyle considerations. ${ }^{3-5}$ Given the need for more long-term data in this surgical cohort, we reviewed our institutional outcomes with aortic valve replacement procedures in patients aged 30 years or younger. Our primary objectives were to define long-term valve hemodynamic profiles, durability, and survival stratified by valve type in this young patient population aged 30 years or younger.

\section{METHODS}

\section{Patients}

This study was approved by our institutional review board. From 1998 to 2016, 99 patients between age 16 and 30 years, inclusive, who did not meet criteria for valve repair underwent an elective aortic valve or composite valve root replacement for valvulopathy. All urgent and emergent procedures were excluded. All patients undergoing primary valve repair and valve sparing root reimplantation were excluded from this study. To account for the heterogeneous disease processes underlying aortic valvulopathy, we stratified the patient population by type of aortic valve replacement (AVR) (41 patients received a biologic/bioprosthetic valve and 58 patients received a mechanical valve), and by the valve size ( $\leq 21 \mathrm{~mm}$ vs $\geq 23 \mathrm{~mm}$ ). In this study, bioprosthetic refers to both stentless and stented tissue AVR.

\section{Clinical and Echocardiographic Follow-up}

Patients were contacted to ensure accurate follow-up. Patients followed at our Aortic Valve Center had prospectively collected clinical and imaging follow-up. For those patients not primarily followed at our institution, transthoracic echocardiographic and clinical data were obtained from their primary care physicians and cardiologists. Total follow-up was 493 patient years.

\section{Valve Selection}

The decision of valve choice was made individually between patient and surgeon based on lifestyle choice, desire for pregnancy, and/or contraindication/desire to avoid anticoagulation therapy.

\section{Statistical Analysis}

General statistics, multivariate models, and graphs were coded in STATA/MP version 14.2 (StataCorp, College Station, Tex). First, data were checked for normality. Descriptive statistics were presented as mean \pm standard deviation for continuous variables, median (interquartile range) for continuous variables in cases of nonnormality, and percentage (frequency) for categorical variables. Continuous variables were compared using the unpaired $t$ test, 1-way analysis of variance and Wilcoxon signedrank test in cases of nonnormality. Fisher exact test and $\chi^{2}$ statistics were used to compare categorical variables. All tests were 2 -sided with the alpha level set at 0.05 for statistical significance.

Competing-risk regression was fitted with aortic valve reoperation as dependent variable. Covariates were age, gender, valve type (bioprosthetic vs mechanical), valvular morphology at baselines (tricuspid aortic valve $[\mathrm{TAV}]$ vs bicuspid aortic valve [BAV]), and prosthetic valve size (as continuous variable). Competing risk of mortality was taken into account. Cumulative incidences were plotted stratified by prosthetic valve type and prosthetic valve size $(\leq 21 \mathrm{~mm}$ vs $23-31 \mathrm{~mm})$.

Threshold regression was used to identify a sample split in prosthetic valve size as risk factor for aortic valve reoperation. Reoperation was used as the dependent variable (binary), independent variables were age, gender, valve type (bioprosthetic vs mechanical valve), and valvular morphology at baseline (TAV vs BAV). Prosthetic valve size (as continuous variable) was introduced as the threshold variable and model was run with 5000 bootstrap replications, default White correction for heteroscedasticity indicator was used. Graph of the normalized likelihood ratio statistic as a function of the threshold in prosthetic valve size is outlined in Figure 1.

A linear mixed-effects model was fitted to assess trends in mean aortic valve pressure gradient patterns over postoperative follow-up time and to validate risk factors associated with progression of mean aortic valve pressure gradients. Postoperative time course (time as continuous variable), age, gender, valve type (bioprosthetic vs mechanical), valvular morphology at baseline (TAV vs BAV) and prosthetic valve size (categorical $\leq 21 \mathrm{~mm}$ vs $\geq 23 \mathrm{~mm}$ ) were included as fixed effects with a random-intercept term at the patient level with a random slope on the postoperative time course. Covariance structure for random effects was unstructured. Model was fit using maximum likelihood. Default gradient-based Newton Raphson iterations were used.

Kaplan-Meier method and log-rank statistics were used to determine, compare and plot survival estimates (Figure 2) stratified by valve type (plotted with 95\% confidence interval bands). One-, 5-, and 10-year freedom from reoperation and freedom from mortality were reported actuarially.

\section{RESULTS}

\section{Patient Population and Preoperative Parameters}

Demographic characteristics and preoperative parameters are listed in Table 1. In total, 99 patients met inclusion 


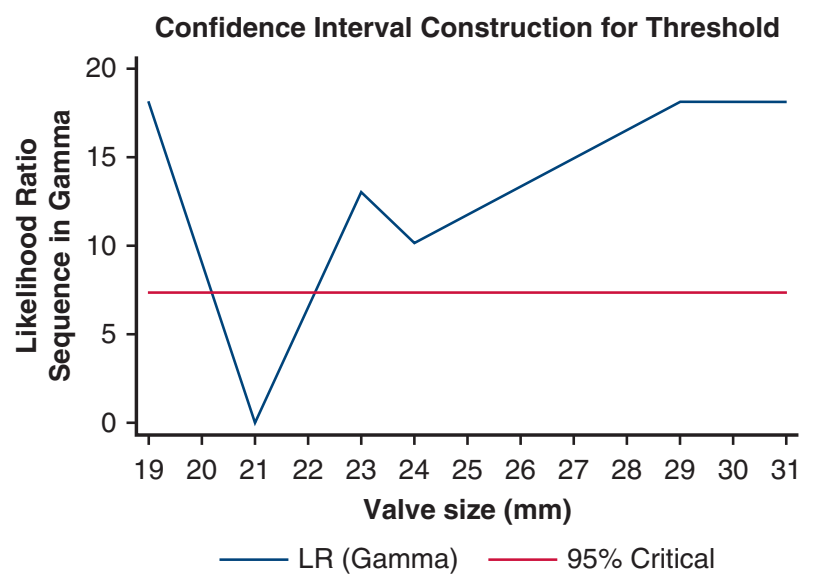

FIGURE 1. Threshold regression. Normalized likelihood ratio (LR) as a function of aortic valve replacement size.

criteria with a total follow-up of 493 patient years. Average age at valve implantation was $24.7 \pm 3.2$ years for mechanical aortic valve and $24.5 \pm 3.0$ years for biologic/bioprosthetic aortic valve. Patients were stratified according to tissue versus mechanical valve implantation. We observed a rather homogenous patient population at baseline with only a few differences between groups. There was no significant difference in the number or type of previous valve interventions. Indications for primary and reoperative valve surgery were not significantly different between the Mechanical and Biologic/Bioprosthetic groups (Table 1). Preoperative echocardiographic parameters differed in peak aortic transvalvular pressure gradient $(P=.03)$. However, no significant differences in mean aortic transvalvular pressure gradient $(P=.07)$, or left ventricular end-diastolic dimension $(P=.05)$ existed between groups (Table 1).

\section{Intraoperative Data and Postoperative Outcomes}

There were 3 primary aortic valve procedures: AVR, AVR and supracoronary ascending aortic replacement, and aortic root replacement (ARR) (Video 1). There was no significant difference between the percentages of mechanical and biologic/bioprosthetic valves utilized in AVR or ARR procedures, but more female patients underwent biologic/bioprosthetic AVR/ARR $(P=.002)$, and a significantly higher subpopulation of BAV patients received a biologic/bioprosthetic valve $(P=.01)$ (Table 1$)$. There were significantly more biologic/bioprosthetic valves placed for AVR and supracoronary ascending aortic replacement $(P=.03$ ) (Table 2$)$. Implant valve size was similar $(P=.29)$. In-hospital/30-day mortality, stroke, renal failure, and reoperation for bleeding rates were also similar (Table 2).

\section{Follow-up}

Median clinical and echocardiographic follow-up was similar between groups (Table 2). Total median follow-up for the entire group was 49 months (interquartile range, 16-97 months).

\section{Indications and Risk Factors for AVR}

There was no significant difference in indications for reoperation by AVR type (Table 3). The most common

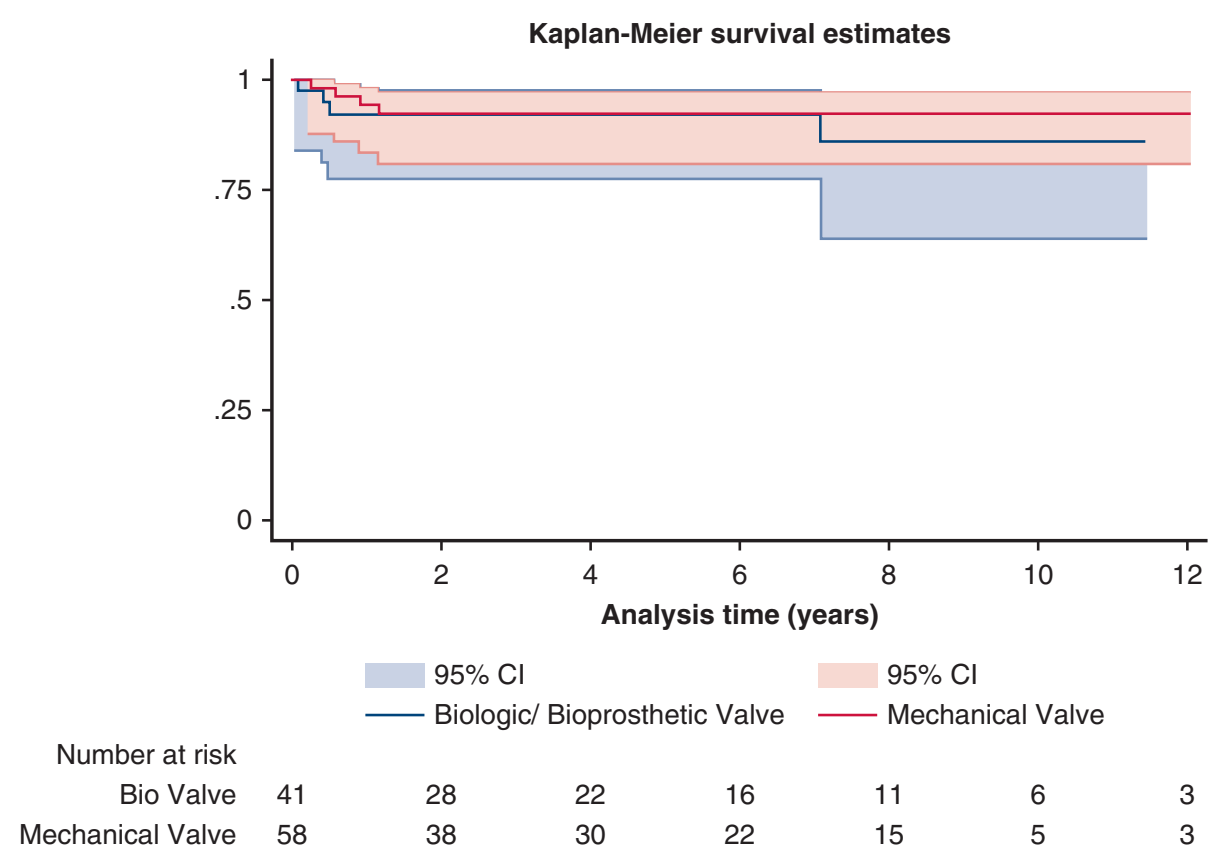

FIGURE 2. Kaplan-Meier survival estimates stratified valve type. $\log \operatorname{rank} P=.597$. $C I$, Confidence interval. 
TABLE 1. Demographic characteristics and preoperative parameters

\begin{tabular}{|c|c|c|c|}
\hline Variable & Mechanical valve $(n=58)$ & Bioprosthetic valve $(n=41)$ & $P$ value \\
\hline \multicolumn{4}{|l|}{ Demographic characteristic } \\
\hline Age & $24.7 \pm 3.2$ & $24.5 \pm 3.0$ & .69 \\
\hline Male gender & $49(84.5)$ & $23(65.1)$ & $<.01$ \\
\hline BAV & $29(50)$ & $30(73.2)$ & .01 \\
\hline BMI & $26.6 \pm 7.1$ & $25.1 \pm 5.9$ & .29 \\
\hline Previous native valve procedure & $\mathrm{n}=12$ & $\mathrm{n}=8$ & \\
\hline Valvuloplasty, open & $2(16.7)$ & $2(25.0)$ & .65 \\
\hline Valvuloplasty, balloon & $1(8.3)$ & $3(37.5)$ & .11 \\
\hline Ross procedure & $5(41.7)$ & $1(12.5)$ & .16 \\
\hline Primary valve repair & $2(16.7)$ & $2(25.0)$ & .65 \\
\hline VSRR & $2(16.7)$ & $0(0)$ & .22 \\
\hline \multicolumn{4}{|l|}{ Echocardiographic data } \\
\hline Mean AV gradient (mm Hg) & $15.8 \pm 13.9$ & $29.2 \pm 20.5$ & .07 \\
\hline Peak AV gradient (mm Hg) & $27.1 \pm 21.5$ & $53.7 \pm 36.1$ & .03 \\
\hline $\operatorname{LVEDD}(\mathrm{mm})$ & $63.6 \pm 8.7$ & $58.1 \pm 10.3$ & .05 \\
\hline $\mathrm{EF}(\%)$ & $51.7 \pm 15.2$ & $57.6 \pm 11.3$ & .11 \\
\hline Surgical indication at index operation & $\mathrm{n}=58$ & $\mathrm{n}=41$ & \\
\hline TAV-AS & $1(1.7)$ & $0(0)$ & .40 \\
\hline TAV-AI & $7(12.1)$ & $2(4.9)$ & .22 \\
\hline BAV-AS & $10(17.2)$ & $12(29.3)$ & .16 \\
\hline BAV-AI & 9 (15.5) & $10(24.4)$ & .27 \\
\hline Marfan syndrome & $8(13.8)$ & $2(4.9)$ & .15 \\
\hline Endocarditis & $20(34.5)$ & $13(31.7)$ & .77 \\
\hline Rheumatic valve degeneration & $3(5.2)$ & $2(4.9)$ & .95 \\
\hline
\end{tabular}

Data are presented as mean \pm standard deviation or n (\%). BAV, Bicuspid aortic valve, $B M I$, body mass index; VSRR, valve sparing root replacement; $A V$, aortic valve; $L V E D D$, left ventricular end-diastolic dimensions; $E F$, ejection fraction; $T A V$, tricuspid aortic valve; $A S$, aortic stenosis; $A I$, aortic insufficiency.

indication in both groups was endocarditis, followed by biologic/bioprosthetic structural valve deterioration, and mechanical valve dysfunction. To further understand risk factors for aortic reoperation, we fitted a competing-risk regression model, taking into account the competing-risk of mortality (Table 4). Covariate structure for this model is detailed in the Methods section. The type of valve implant (biologic/bioprosthetic vs mechanical valve) and aortic valve morphology at baseline (BAV vs TAV) were not associated with increased risk of reoperation (subdistribution hazard ratio [SHR], $1.72[P=.18]$ and SHR, 1.32 $[P=.57]$, respectively). The SHR for AVR size was $<1$, and statistically significant $(P=.04)$, suggesting that small valve size was a significant independent risk factor for aortic valve reoperation.

\section{Effect of Prosthetic Valve Size and AVR Type on Aorta Reoperation}

Using AVR size as a continuous variable did not permit the identification of the exact valve size or range of valve sizes that carry the highest risk for aortic valve reoperation. A threshold regression analysis identified a single sample split at $\leq 21 \mathrm{~mm}$ AVR size, suggesting that prosthetic valve sizes of $19 \mathrm{~mm}$ and $21 \mathrm{~mm}$ have the highest risk of reoperation (Figure 1). Covariate structure is outlined in the Methods section and a graph of the normalized likelihood ratio statistic as a function of the threshold in AVR size is outlined in Figure 1. Based on the threshold of $\leq 21 \mathrm{~mm}$ valve size, a cumulative incidence plot was constructed to better understand the pattern of prosthetic valve failure over follow-up stratified by valve size $(\leq 21 \mathrm{~mm}$ vs 23 $31 \mathrm{~mm}$ ) and valve type (biologic/bioprosthetic vs mechanical valve) (Figure 3$)$. Smaller AVR sizes ( $\leq 21 \mathrm{~mm})$ were associated with a 1.9-fold increased risk of aortic valve

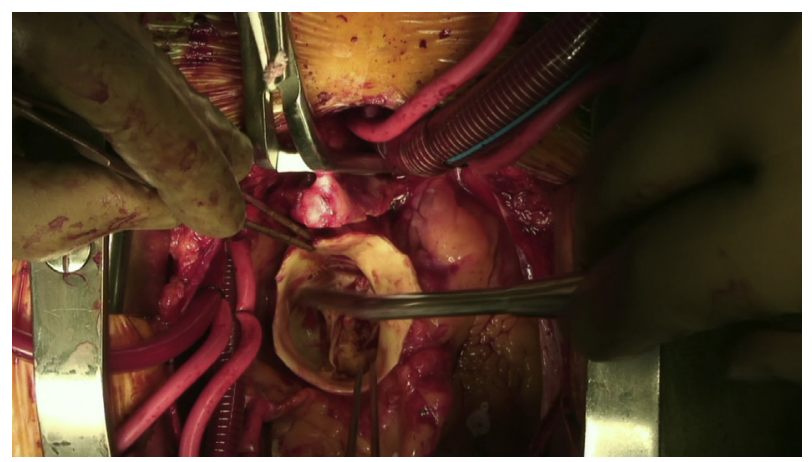

VIDEO 1. Intraoperative video demonstrating aortic valve replacement with a bioprosthetic valve for aortic stenosis and aortic insufficiency in a patient with bicuspid aortic valve disease. Video available at: https:// www.jtcvs.org/article/S0022-5223(18)32933-7/fulltext. 
TABLE 2. Intraoperative data and postoperative outcomes

\begin{tabular}{|c|c|c|c|}
\hline Variable & Mechanical valve $(\mathbf{n}=\mathbf{5 8})$ & Bioprosthetic valve $(n=41)$ & $P$ value \\
\hline \multicolumn{4}{|l|}{$\mathrm{AV}$ procedure } \\
\hline AVR & $33(56.9)$ & $24(58.5)$ & .87 \\
\hline AVRSCAAR & $1(1.7)$ & $5(12.2)$ & .03 \\
\hline ARR & $24(41.4)$ & $12(29.3)$ & .22 \\
\hline \multicolumn{4}{|l|}{ Concomitant procedure } \\
\hline Ventricular septal defect & $2(3.4)$ & $3(7.3)$ & .39 \\
\hline Atrial septal defect & $2(3.4)$ & $2(4.9)$ & .72 \\
\hline Mitral valve repair/replacement & $11(19.0)$ & $2(4.9)$ & .04 \\
\hline \multicolumn{4}{|l|}{ Intraoperative parameter } \\
\hline Crossclamp (min) & $148.8 \pm 67.9$ & $121.8 \pm 57.1$ & .04 \\
\hline Bypass time (min) & $197.8 \pm 87.0$ & $173.7 \pm 103.8$ & .22 \\
\hline \multicolumn{4}{|l|}{ Valve characteristic } \\
\hline Median valve size (mm) & $25(23-27)$ & $23(21-27)$ & .29 \\
\hline \multicolumn{4}{|l|}{ Postoperative outcome } \\
\hline In-hospital/30-d mortality & $1(1.7)$ & $2(4.9)$ & .35 \\
\hline Stroke & $1(1.7)$ & $0(0)$ & .41 \\
\hline TIA & $1(1.7)$ & $1(2.4)$ & .80 \\
\hline Renal failure & $0(0)$ & $1(2.4)$ & .22 \\
\hline Reoperation for bleeding & $1(1.7)$ & $0(0)$ & .51 \\
\hline \multicolumn{4}{|l|}{ Follow-up } \\
\hline Median follow-up (mo) & $50.0(15.8-97.5)$ & $48.0(16.0-97.0)$ & .98 \\
\hline Median echocardiographic follow-up & $47.0(16.0-89.5)$ & $41.0(6.0-97.0)$ & .81 \\
\hline
\end{tabular}

Data are presented as mean \pm standard deviation, median (interquartile range), or n (\%). $A V$, Aortic valve; $A V R$, aortic valve replacement; $A V R S C A A R$, aortic valve replacement with supracoronary ascending aorta replacement; $A R R$, aortic root replacement; TIA, transient ischemic attack.

reoperation $(P=.04)$, but the valve type had no effect over follow-up time $(P=.18)$.

\section{Effect of Valve Type and Size on Longitudinal Mean Aortic Transvalvular Gradient Trends}

Raw data of mean transvalvular aortic valve gradients over follow-up are plotted in Figure 4, stratified by valve type, valve size, and whether the patient was undergoing primary valve replacement or aortic valve reoperation. To validate factors associated with mean gradient trends over time, a repeated measures mixed effects longitudinal model was fitted (Table 5). Mixed effects, random effects, random effects covariate structure, and interaction terms are specified in the Methods section. The coefficient on

TABLE 3. Indications for reoperation

\begin{tabular}{lccc}
\hline \multicolumn{1}{|c}{ Indication for reoperation } & $\begin{array}{c}\text { Mechanical } \\
\text { valve } \\
(\mathbf{n}=\mathbf{5 8})\end{array}$ & $\begin{array}{c}\text { Bioprosthetic } \\
\text { valve } \\
(\mathbf{n}=\mathbf{4 1})\end{array}$ & $\begin{array}{c}\boldsymbol{P} \\
\text { valve }\end{array}$ \\
\hline Total reoperations & 13 & 12 & - \\
$\begin{array}{l}\text { Biologic/bioprosthetic valve } \\
\text { degeneration or mechanical } \\
\text { valve dysfunction }\end{array}$ & $4(30.8)$ & $6(50)$ & .33 \\
\hline $\begin{array}{l}\text { Patient-prosthesis mismatch } \\
\text { Endocarditis }\end{array}$ & $0(0)$ & $1(8.3)$ & .29 \\
\hline Connective tissue disease & $7(53.8)$ & $5(41.7)$ & .54 \\
\hline
\end{tabular}

Data are presented as $\mathrm{n}$ or $\mathrm{n}(\%)$. postoperative time was positive (coefficient $=1.54$ ) and highly significant $(P<.01)$, suggesting that there was a significant increase in mean aortic valve gradients over time (Figure 5). But overall, both valve types showed similar transvalvular mean pressure gradients $(P=.25)$. Small AVR $(\leq 21 \mathrm{~mm})$ was significantly associated with increased mean aortic valve pressure gradients over time (coefficient, $7.1 ; P<.01$ ) (Figure 5). Overall, mean aortic valve pressure gradients are expected to exceed $20 \mathrm{~mm} \mathrm{Hg}$ after 8 years in the Biologic/Bioprosthetic Valve group, and after 9.5 years in the Mechanical Valve group (Figure 5).

\section{Survival and Freedom From Reoperation}

One-, 5-, and 10-year actuarial freedom from reoperation by valve type was $89.1 \%, 84.6 \%$, and $69.4 \%$ for the Mechanical Valve group, and $89.6 \%, 70.9 \%$, and $57.6 \%$ for the Biologic/Bioprosthetic Valve group, respectively (log rank $P=.279$ ). One, 5-, and 10-year actuarial survival stratified by prosthetic valve type was $94.5 \%, 92.3 \%$, and $92.3 \%$ for the Mechanical Valve group and $92.2 \%$, $92.2 \%$, and $85.4 \%$ for Biologic/Bioprosthetic Valve group, respectively ( $\log \operatorname{rank} P=.597$ ) (Figure 2 ).

\section{DISCUSSION}

Aortic valvulopathy in children and young adults is a lifelong disease. After AVR, progressive left ventricular dysfunction, prosthetic valve degeneration or dysfunction 
TABLE 4. Competing risk regression

\begin{tabular}{lccc}
\hline \multicolumn{1}{c}{ Variable } & $\begin{array}{c}\text { Subdistribution } \\
\text { hazard ratio }\end{array}$ & $\begin{array}{c}\mathbf{9 5} \% \text { Confidence } \\
\text { interval }\end{array}$ & $\begin{array}{c}\boldsymbol{P} \\
\text { value }\end{array}$ \\
\hline Age & 0.91 & $0.81-1.03$ & .14 \\
Female gender & 1.23 & $0.51-2.96$ & .64 \\
$\begin{array}{l}\text { Biologic/bioprosthetic vs } \\
\text { mechanical valve }\end{array}$ & 1.72 & $0.78-3.78$ & .18 \\
$\begin{array}{l}\text { Valve size } \\
\quad \text { continuous variable) }\end{array}$ & 0.86 & $0.74-1.00$ & .04 \\
BAV vs TAV & 1.32 & $0.51-3.44$ & .57 \\
\hline
\end{tabular}

$B A V$, Bicuspid aortic valve; $T A V$, tricuspid aortic valve.

requiring reoperation, and complications associated with valve replacement are risks throughout adulthood. Young adults differ from the pediatric population in that somatic growth is not a primary determinant of aortic valve procedure choice. However, these young patients are at risk for major adverse prosthetic valve-related events that include structural biologic/bioprosthetic valve deterioration; mechanical valve dysfunction; endocarditis; and paravalvular leak with associated hemolysis leading to anemia, bleeding, and thromboembolic events. ${ }^{4,5}$ Therefore, therapeutic management plans require lifetime surveillance. For patients with nonrepairable aortic valves, recommendations for the optimal aortic valve prosthesis/procedure are not clear and, specifically, the long-term clinical and functional valvular outcomes are not as well understood in this young patient population. As a result, these are often complex and multifactorial decisions undertaken together by a patient, cardiologist, and surgeon. ${ }^{4,5}$ Important considerations include the patient's age, gender, lifestyle, occupation, medical adherence, dimensions of the aortic root complex, left ventricular function, need for and degree of anticoagulation, risk of surgery and postoperative anticoagulation, and the longterm risk/benefit assessment of valve durability (vs reoperation) and anticoagulation (thromboembolic vs bleeding events). ${ }^{4,5}$

A logistic problem with current recommendations for mechanical or bioprosthetic valves in young adults is that most studies that evaluate the valve risk/benefit, durability, and outcomes have been extrapolated from either a pediatric or older patient population, with few studies delineating these results in the young adult population. ${ }^{5}$ All prosthetic aortic valves have limitations with suboptimal long-term results. ${ }^{1}$ An ideal AVR for this young population therefore would include a valve that has lifelong durability, is available off-the-shelf in all necessary sizes, has excellent hemodynamic parameter profiles, is easily implantable, requires no anticoagulation therapy, and has no risk of thromboembolic events. ${ }^{4}$

The 2017 American College of Cardiology/American Heart Association guidelines for the use of mechanical valves have been modified with respect to age, prosthetic valve, and anticoagulation recommendations for patients younger than age 50 years who have absolute contraindications, inability to manage anticoagulation, or personal aversion to anticoagulation therapy. ${ }^{6}$ However, despite these less rigorous age guidelines, in the current era few young adults want to receive anticoagulation therapy or alter their lifestyle. ${ }^{5}$ Furthermore, women who want to have children despite close monitoring of anticoagulation ${ }^{7}$ choose a biologic/bioprosthetic valve. Aortic valve repair procedures have gained momentum in young patients over the past several years ${ }^{2,8,9}$; however, lifetime durability in a patient

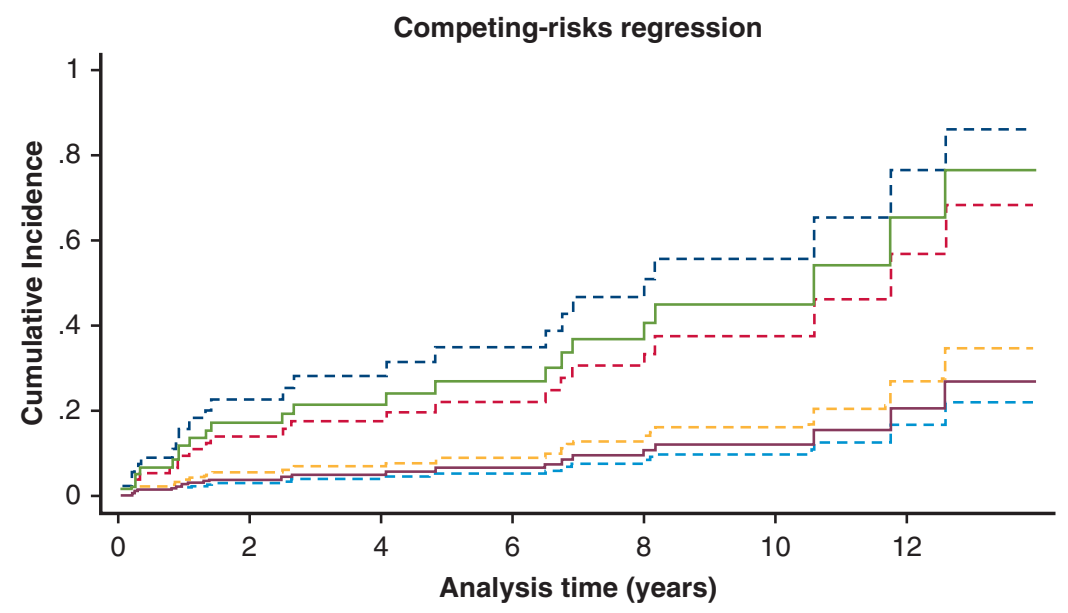

$$
\begin{array}{ll}
\text { - - - Biologic/ Bioprosthetic, Valve Size } \leq 21 \mathrm{~mm} & - \text { - } \text { Biologic/ Bioprosthetic, Valve Size } \geq 23 \mathrm{~mm} \\
\text { - - - Mechanical Valve, Valve Size } \leq 21 \mathrm{~mm} \quad \text { - - Mechanical Valve, Valve Size } \geq 23 \mathrm{~mm} \\
\text { - Valve Size } \leq 21 \mathrm{~mm} & - \text { Valve Size } \geq 23 \mathrm{~mm}
\end{array}
$$

FIGURE 3. Competing-risk cumulative incidence of reoperation. Incidence of reoperation does not depend on aortic valve replacement type (biologic/ bioprosthetic vs mechanical) but rather on aortic valve replacement size. 


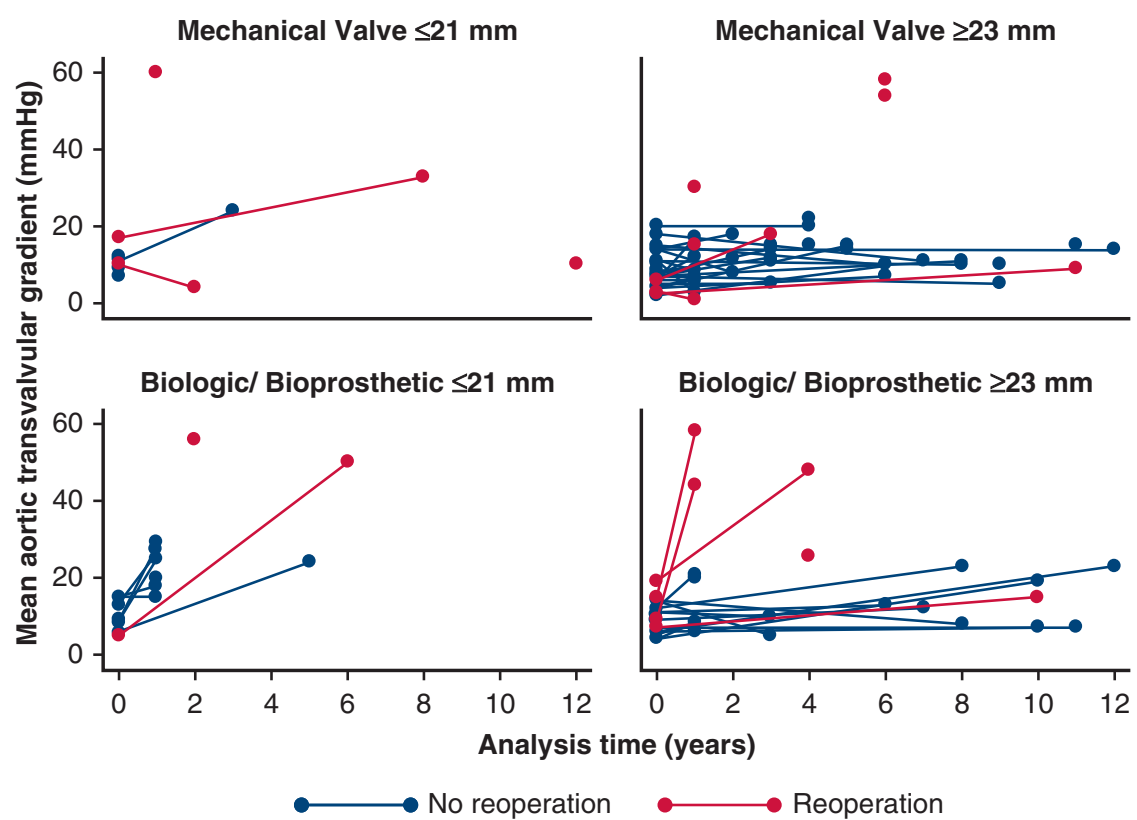

FIGURE 4. Spaghetti plot. Mean aortic transvalvular gradients stratified by aortic valve replacement type and size ( $\leq 21 \mathrm{~mm} v \mathrm{vs} 23-31 \mathrm{~mm})$. Plot shows patients who did not require aortic valve reoperation (blue) and patients who underwent reoperation (red).

younger than age 30 years has not been as well established. The recent rise of transcatheter valve procedures has prompted the recommendation of transcatheter valve-invalve for structural valve disease of bioprosthetic valves. However, long-term durability of the valve-in-valve procedure in a young adult may be less than optimal, requiring multiple procedures and increased risk of heart block as well as PPM by middle age. ${ }^{5,10,11}$ Given these concerns, the primary objective of our study was to identify factors that influence the use of either mechanical or biologic/ bioprosthetic AVR in young adults and to analyze mid- to long-term outcomes in these patients.

For young adults with irreparable aortic valvulopathy, a mechanical valve has the benefit of potentially providing

TABLE 5. Repeated measures, mixed-effects longitudinal model. Factors associated with mean transvalvular aortic valve gradients over follow-up

\begin{tabular}{lccc}
\hline \multicolumn{1}{c}{ Variable } & Coefficient & Standard error & $\boldsymbol{P}$ value \\
\hline $\begin{array}{l}\text { Prosthesis size } \leq 21 \mathrm{~mm} \text { vs } \\
\text { 23-31 mm }\end{array}$ & 7.10 & 2.48 & $<.01$ \\
Postoperative time course & 1.54 & 0.37 & $<.01$ \\
$\begin{array}{l}\text { Biologic/bioprosthetic vs } \\
\text { mechanical valve }\end{array}$ & 2.32 & 2.0 & .25 \\
BAV vs TAV & 1.33 & 1.93 & .49 \\
Age & -0.36 & 0.31 & .24 \\
Female gender & -1.54 & 2.28 & .50 \\
\hline
\end{tabular}

$B A V$, Bicuspid aortic valve; $T A V$, tricuspid aortic valve. long-term durability. However, mechanical valves do not carry a $100 \%$ freedom from reoperation, and long-term survival is lower than that seen in age-matched and gendermatched control cohorts. ${ }^{12}$ Risks of paravalvular leak, hemolysis, thromboembolic events, bleeding, PPM, and pannus formation are well documented. ${ }^{1,12-14}$ In pediatric and young adult patient populations, studies have reported 12- to 20 -year survival of $75 \%$ to $92 \%,{ }^{13,15,16}$ and 15 - to 20 -year freedom from reoperation of $55 \%$ to $94 \%$ for a mechanical valve for all aortic valve pathologies. ${ }^{13,15-19}$ Although the freedom from reoperation has improved in the recent era, it is not absolute, ${ }^{1}$ and therefore mechanical aortic valve implantation may not be considered a lifetime cure for aortic valve pathology in this cohort. ${ }^{11,12}$ There is a constant hazard of mechanical valve dysfunction requiring reoperation, thromboembolic events, and bleeding. ${ }^{12,14,17}$ Thromboembolic events are reported to occur at a linearized rate of $1.5 \%$ to $2 \%$ per patient year, and bleeding events occur at a linearized rate of about $3 \%$ per patient year. ${ }^{14,17,20}$ Although these rates are low, the accrual rate over time comprises a major disadvantage to mechanical aortic valves. ${ }^{14,20}$ In our study, $58.6 \%$ patients had a mechanical valve placed with a 1-, 5-, and 10-year actuarial freedom from reoperation of $89.1 \%, 84.6 \%$, and $69.4 \%$, and survival of $94.5 \%, 92.3 \%$, and $92.3 \%$, respectively. Thromboembolic and bleeding rates were seen in $1.7 \%$ of the cohort.

Compared with mechanical valves, biologic/bioprosthetic valves have a low thromboembolic risk and do 


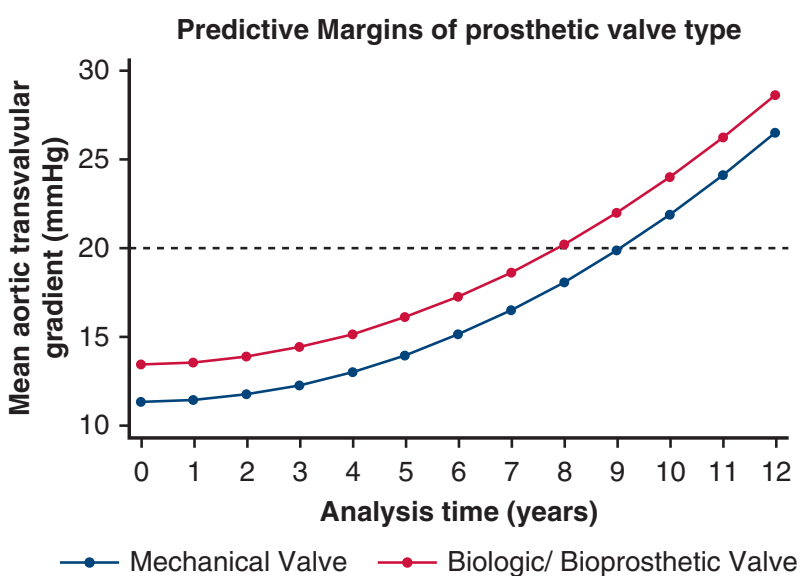

FIGURE 5. Predicted progression of mean aortic transvalvular gradients stratified by aortic valve replacement type. Mean aortic transvalvular gradients increase over time $(P \leq .01)$ but do not differ between groups $(P=.25)$.

not mandate lifelong anticoagulation. ${ }^{11,13}$ However, biologic/bioprosthetic valves have a known risk of structural valve deterioration and variable freedom from reoperation that is closely related to patient age. ${ }^{11,13,17,21,22}$ The pediatric and young adult populations are at risk for accelerated valve deterioration. ${ }^{5,11,21-24}$ In this young patient population, multiple investigations have reported a variable 10- to 15-year freedom from reoperation of $35 \%$ to $79 \%,{ }^{11,13,15,17,18,21}$ with a 10 - to 12 -year survival of $85 \%$ to $92 \%,{ }^{13,15}$ and a $100 \% 10$-year freedom from thromboembolic/bleeding events ${ }^{13}$ for all aortic valve pathologies. However, each new generation of stented bioprosthetic valves employing innovative fixation and antimineralization processes has a reported improved 10-year freedom from reoperation. ${ }^{11,22,23}$ Furthermore, studies have shown that reoperative AVR carries a similar perioperative mortality risk as first-time AVR, ${ }^{11,25,26}$ and bioprosthetic implantation at reoperative AVR yields the equivalent survival as mechanical valve in the first AVR. ${ }^{11,25}$ Thus, biologic/bioprosthetic aortic valves are increasingly becoming a rational choice in both young and older adult patients. ${ }^{11}$ This is especially relevant in young patients with lifestyle considerations and in young women considering future pregnancies. In our study, we observed 1-, 5-, and 10-year actuarial freedom from reoperation of $89.6 \%, 70.9 \%$, and $57.6 \%$, and actuarial survival of $92.2 \%, 92.2 \%$, and $85.4 \%$, respectively, in our Biologic/Bioprosthetic cohort.

Identification of factors that influence prosthetic valve use and outcomes is critical in this young adult population. It is becoming evident that hemodynamic profile has a major influence on prosthetic valve durability and longitudinal outcomes. $^{11,13,22}$ Echocardiographic delineation of effective orifice area indexed to body surface area of the prosthetic aortic valve using a 3-tier method has been utilized to identify PPM. ${ }^{24,27,28}$ The influence of PPM on left ventricular function, exercise capacity, and need for reoperation in the young patient population is well established, emphasizing the need to select a prosthetic valve with optimal effective orifice area at implant. ${ }^{1,13,24,28,29}$ Moon and colleagues ${ }^{28}$ reported a negative influence in survival with moderate PPM $\left(0.75 \mathrm{~cm}^{2} / \mathrm{m}^{2}\right)$ in young adults. Furthermore, recent studies by Rosu and colleagues $^{11}$ and Johnston and colleagues ${ }^{22}$ found that $10 \mathrm{~mm} \mathrm{Hg}$ increase in postoperative peak gradient was associated with a $>2$-fold increase in 20-year risk for reoperation.

In our study, we evaluated valve-related hemodynamic factors that influenced freedom from reoperation in both the Mechanical and Biologic/Bioprosthetic valve groups. Specifically, we investigated the effect of valve type and size on longitudinal mean aortic transvalvular gradients. We delineated a single sample split at $\leq 21 \mathrm{~mm}$ aortic valve replacement size, and identified that prosthetic valve sizes of $19 \mathrm{~mm}$ and $21 \mathrm{~mm}$ had a 1.9 -fold increased risk of aortic valve reoperation over time, compared to larger valve sizes. For both mechanical and biologic/bioprosthetic valves, there was a significant increase in mean aortic transvalvular gradient over time (20 $\mathrm{mm} \mathrm{Hg}$ after 8 years for the Biologic/Bioprosthetic Valve cohort, and $20 \mathrm{~mm} \mathrm{Hg}$ after 9.5 years for the Mechanical Valve cohort), but no significant difference between the Mechanical versus Biologic/Bioprosthetic groups was noted. Therefore, it is clear that small AVR size $(\leq 21 \mathrm{~mm})$ is associated with a significant increase in mean aortic valve pressure gradients over time, and importantly, AVR size $(\leq 21 \mathrm{~mm})$ is a significant risk factor for reoperation.

Therefore, in this study cohort, likelihood of reoperation for patients aged 30 years or younger was more dependent upon size of the valve as opposed to type of valve. This supports the concept that in young adults with small aortic root complex dimensions, aortic root and annular enlargement procedures should be considered to optimize the effective orifice area and minimize PPM, especially in the elective setting. Special consideration might also be given toward left ventricular outflow tract enlargement procedures as needed in those patients who otherwise cannot accommodate a valve $>21 \mathrm{~mm}$.

\section{Limitations}

As with all retrospective studies, extensive work was done to obtain echocardiographic data for long-term outcome analysis; however, complete follow-up on all patients was not possible. Multiple attempts were made to contact all patients, their primary care physicians, and their cardiologists to obtain complete follow-up data. Due to referral patterns, centralized and standardized echocardiographic reads by 1 echocardiographer were not possible, which may contribute 
to variability in technique, operator bias, and reader bias. Finally, the overall cohort size was not large enough to perform reliable propensity score matching due to sample size. A multi-institutional investigation may help address this concern.

\section{CONCLUSIONS}

Our results suggest that the choice of mechanical versus biologic valve does not affect freedom from reoperation or survival rates in young patients (aged 30 years or younger) at mid- to long-term follow-up. AVR size is a significant risk factor for reoperation and progression of mean aortic valve gradients. Although smaller prosthetic valve sizes $(\leq 21 \mathrm{~mm})$ are associated with a significantly higher risk of aortic valve reoperation, valve type, preoperative valve anatomy, or pathology have no significant effect over follow-up. Further longitudinal follow-up may elucidate the relative risks of mechanical aortic and biologic/bioprosthetic valves in this young patient cohort. A prospective and matched study with the latest generation biologic/bioprosthetic valves will be important to understand optimal valve choice in young patient populations.

\section{Webcast}

You can watch a Webcast of this AATS meeting presentation by going to: https://aats.blob.core.windows.net/ media/17AM/2017-05-02/RM312/05-02-17_Room312_ 1438_Milewski.mp4.

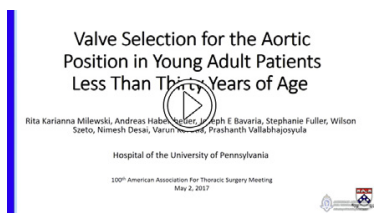

\section{Conflict of Interest Statement}

Authors have nothing to disclose with regard to commercial support.

\section{References}

1. Etnel JR, Elmont LC, Ertekin E, Mokhles MM, Heuvelman HJ, RoosHesselink JW, et al. Outcome after aortic valve replacement in children: a systematic review and meta-analysis. J Thorac Cardiovasc Surg. 2016;151:143-52.

2. Vricella LA, Cameron DE. Valve-sparing aortic root replacement in pediatric patients: lessons learned over two decades. Semin Thorac Cardiovasc Surg Pediatr Card Surg Annu. 2017;20:56-62.

3. Khan MS, Samayoa AX, Chen DW, Petit CJ, Fraser CD Jr. Contemporary experience with surgical treatment of aortic valve disease in children. J Thorac Cardiovasc Surg. 2013;146:512-20.

4. Rahimtoola SH. Choice of prosthetic heart valve in adults an update. J Am Coll Cardiol. 2010;55:2413-26.

5. Jaquiss RD. Bioprosthetic aortic valve replacement in the young: a cautionary tale. Circulation. 2014;130:7-9.

6. Nishimura RA, Otto CM, Bonow RO, Carabello BA, Erwin JP III, Fleisher LA, et al. 2017 AHA/ACC focused update of the 2014 AHA/ACC guideline for the management of patients with valvular heart disease: a report of the American College of Cardiology/American Heart Association Task Force on clinical practice guidelines. Circulation. 2017;135:e1159-95.
7. Hassouna A, Allam H. Limited dose warfarin throughout pregnancy in patients with mechanical heart valve prosthesis: a meta-analysis. Interact Cardiovasc Thorac Surg. 2014;18:797-806.

8. Bavaria JE, Desai N, Szeto WY, Komlo C, Rhode T, Wallen T, et al. Valvesparing root reimplantation and leaflet repair in a bicuspid aortic valve: comparison with the 3-cusp David procedure. J Thorac Cardiovasc Surg. 2015; 149(Suppl):S22-8

9. Vallabhajosyula P, Szeto WY, Habertheuer A, Komlo C, Milewski RK, McCarthy F, et al. Bicuspid aortic insufficiency with aortic root aneurysm: root reimplantation versus Bentall root replacement. Ann Thorac Surg. 2016;102:1221-8.

10. Dvir D, Webb J, Brecker S, Bleiziffer S, Hildick-Smith D, Colombo A, et al. Transcatheter aortic valve replacement for degenerative bioprosthetic surgical valves: results from the global valve-in-valve registry. Circulation. 2012;126:2335-44.

11. Rosu C, Soltesz EG. Selection of valve prostheses. Semin Thorac Cardiovasc Surg. 2015;27:152-8.

12. Bouhout I, Stevens LM, Mazine A, Poirier N, Cartier R, Demers P, et al. Longterm outcomes after elective isolated mechanical aortic valve replacement in young adults. J Thorac Cardiovasc Surg. 2014;148:1341-6.

13. Alsoufi B. Aortic valve replacement in children: options and outcomes. J Saudi Heart Assoc. 2014;26:33-41.

14. Toole JM, Stroud MR, Kratz JM, Crumbley AJ III, Bradley SM, Crawford FA Jr, et al. Twenty-five year experience with the St. Jude medical mechanical valve prosthesis. Ann Thorac Surg. 2010;89:1402-9.

15. Sharabiani MT, Dorobantu DM, Mahani AS, Turner M, Peter Tometzki AJ, Angelini GD, et al. Aortic valve replacement and the Ross operation in children and young adults. J Am Coll Cardiol. 2016;67:2858-70.

16. Masuda M, Kado H, Ando Y, Shiose A, Nakano T, Fukae K, et al. Intermediateterm results after the aortic valve replacement using bileaflet mechanical prosthetic valve in children. Eur J Cardiothorac Surg. 2008;34:42-7.

17. Bradley SM. Aortic valve insufficiency in the teenager and young adult: the role of prosthetic valve replacement. World J Pediatr Congenit Heart Surg. 2013;4:397-402.

18. Ruel M, Kulik A, Lam BK, Rubens FD, Hendry PJ, Masters RG, et al. Long-term outcomes of valve replacement with modern prostheses in young adults. Eur J Cardiothorac Surg. 2005;27:425-33.

19. Ruzmetov M, Vijay P, Rodefeld MD, Turrentine MW, Brown JW. Evolution of aortic valve replacement in children: a single center experience. Int J Cardiol. 2006;113:194-200.

20. Emery RW, Krogh CC, Arom KV, Emery AM, Benyo-Albrecht K, Joyce LD, et al. The St. Jude Medical cardiac valve prosthesis: a 25-year experience with single valve replacement. Ann Thorac Surg. 2005;79:776-82.

21. Chan V, Malas T, Lapierre H, Boodhwani M, Lam BK, Rubens FD, et al. Reoperation of left heart valve bioprostheses according to age at implantation. Circulation. 2011;124(Supp):S75-80.

22. Johnston DR, Soltesz EG, Vakil N, Rajeswaran J, Roselli EE, Sabik JF III, et al. Long-term durability of bioprosthetic aortic valves: implications from 12,569 implants. Ann Thorac Surg. 2015;99:1239-47.

23. Kaza AK, Pigula FA. Are bioprosthetic valves appropriate for aortic valve replacement in young patients? Semin Thorac Cardiovasc Surg Pediatr Card Surg Annu. 2016;19:63-7.

24. Weber A, Noureddine H, Englberger L, Dick F, Gahl B, Aymard T, et al. Ten-year comparison of pericardial tissue valves versus mechanical prostheses for aortic valve replacement in patients younger than 60 years of age. J Thorac Cardiovasc Surg. 2012;144:1075-83

25. Chan V, Lam BK, Rubens FD, Hendry P, Masters R, Mesana TG, et al. Long-term evaluation of biological versus mechanical prosthesis use at reoperative aortic valve replacement. J Thorac Cardiovasc Surg. 2012;144:146-51.

26. Potter DD, Sundt TM III, Zehr KJ, Dearani JA, Daly RC, Mullany CJ, et al. Operative risk of reoperative aortic valve replacement. J Thorac Cardiovasc Surg. 2005; 129:94-103.

27. Tully PJ, Aty W, Rice GD, Bennetts JS, Knight JL, Baker RA. Aortic valve prosthesis-patient mismatch and long-term outcomes: 19-year single-center experience. Ann Thorac Surg. 2013;96:844-50.

28. Moon MR, Pasque MK, Munfakh NA, Melby SJ, Lawton JS, Moazami N, et al. Prosthesis-patient mismatch after aortic valve replacement: impact of age and body size on late survival. Ann Thorac Surg. 2006;81:481-8.

29. van Slooten YJ, van Melle JP, Freling HG, Bouma BJ, van Dijk AP, Jongbloed MR, et al. Aortic valve prosthesis-patient mismatch and exercise capacity in adult patients with congenital heart disease. Heart. 2016;102:107-13.

Key Words: aortic valve, prosthetic valve 


\section{Discussion}

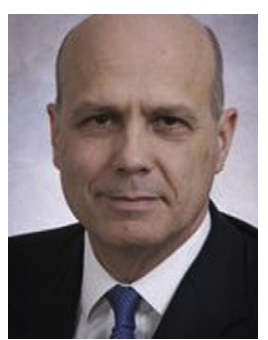

Dr Glenn Van Arsdell (Toronto, Ontario, Canada). I have no disclosures. Dr Milewski and the group from Philadelphia are essentially asking a very important question: What do you do with young patients who are not candidates for a Ross procedure, but for reasons of fertility or activity, need to avoid anticoagulation therapy? Looking at mechanical and tissue valves, no differences in survival, structural valve failure, or reoperation were demonstrated in this cohort. The patients studied were a snapshot of real life: heterogeneous, tricuspids, bicuspids, rheumatics, Marfans, and endocarditis. They were not simple operations, with the average pump times ranging from 166 to 213 minutes, depending on the valve used.

As a surgical discipline, there are 2 key questions for which it would be helpful to know the answer. First, for a noncomplicated aortic valve replacement in a young male patient, is a tissue valve as durable as a mechanical valve? Do your data shed any light on this? For perspective, I might refer back to a Baltimore article from many years ago looking at mechanical valve replacements in patients with Marfan syndrome where the durability of mechanical valves and the reliability was well into $90 \%$ approximately 20 years later, and then in our own practice in isolated young male patients, we have at times put in tissue valves only to be disappointed a few years later having to replace it.

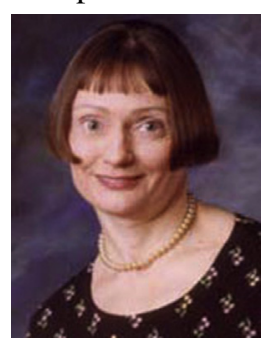

Dr Milewski. That's a very good question. Reflecting on our data, we did not identify anything specific at this point in time, although we do need to look into that more in the future. I think a very important thing to look at-we have not yet-and of course as you are looking at data you always come up with more and more questions, is to look at the era of bioprosthetic valve replacement and look at the generation of valve that was replaced at that time. We have not looked at that yet, but I think that that would be an important factor to look at.

Dr Van Arsdell. The second question that I think is very important and potentially related to the first is that it's conceivable that tissue valve failure could be different between young men and young women. In your study, only $15 \%$ of the mechanical valve patients were female, whereas $44 \%$ of the tissue valve patients were female. Have you done a subanalysis to see if gender is an important factor in tissue valve failure?

Dr Milewski. We have not, but that is another very excellent question and area to look into. The only subanalysis that we have really done was to look at those female patients who had a biological valve placed. We found that it was primarily for pregnancy. Certainly, I think that that would be a very interesting question to look into.

Dr Van Arsdell. Finally, a note on endocarditis. There was a $12 \%$ incidence of postoperative endocarditis, reflective of fully 1-third of patients with a primary operative indication being endocarditis. If I understand your data correctly, your inclusive and exclusive of endocarditis analysis has to do with postoperative endocarditis. Given that all the follow-up parameters could potentially be negatively influenced by the original indications for surgery, did you do a subanalysis looking at your primary end points while excluding preoperative endocarditis cases? So instead of analyzing 99 patients, analyzing 66 patients who didn't come in with endocarditis.

Dr Milewski. We did not do that analysis, but I think that that would be very interesting. I also think it would be interesting to look at referrals from our regional hospitals that are coming in with endocarditis. Another interesting subanalysis for that group of patients would be to look at is if endocarditis is more the result of resistant bacteria, or more from intravenous drug abuse.

Dr Van Arsdell. I would like to thank you for assembling and presenting this thought-provoking data. It is an important question.

Dr Milewski. Thank you.

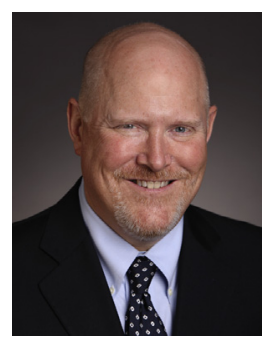

Dr James Tweddell (Cincinnati, Ohio). A very well-presented study that challenges a lot of our preconceptions. Did you notice a differenceI'm certain that you must have-in the modes of valve failure between the 2 types of prostheses: bioprostheses and mechanical valves? Was there a way to assess the rate of failure? Something I think we worry about with bioprosthetic valves is sort of acute catastrophic failure that requires urgent or emergent operation. Was that more frequent with the bioprosthetic valves or the mechanical valves, or did you find relatively equal issues with both?

Dr Milewski. I didn't find anything that was specifically in the emergent situations. There is 1 situation that I can think of specifically. It was a pregnant patient with a bioprosthetic valve who got into trouble right before she delivered and required a Cesarean procedure and then a valve replacement at the same time, and that's the only situation that really comes to mind as far as that goes. But I do believe that is a very interesting question as far as the difference in the causes of valve failure. Obviously, primarily pannus in patients with a mechanical valve, but there were several reasons for failure in the bioprosthetic valve recipients depending on whether 
we were looking at a stented valve or a stentless valve, number 1, and then looking at the manufacturer of valve as well.

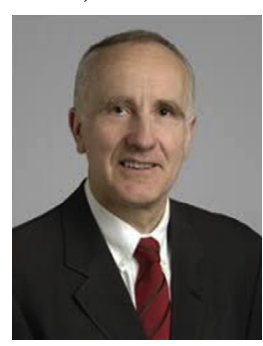

Dr Gosta Pettersson (Cleveland, Ohio). This is a very important study, but we have to remember that this study represent early and midterm outcomes with 10-year follow-up. These are really early failures with limited effect of degeneration of the bioprosthesis.

It is my experience that early reoperations for failure of bioprostheses are driven by high initial gradients and too small valves to begin with. The mode of failure that seems most common, irrespective of choice of valve is formation of a subvalvular pannus. If you start off with a small valve, that valve very quickly becomes stenotic.

The second question I have is related to the choice of valve in patients with endocarditis. In this study you only included patients who had prosthetic valves. Is your preference to use regular prosthetic valves in the majority of patients with endocarditis or do you more often use a Ross procedure or a homograft in those patients?

Dr Milewski. At our institution we perform primarily a prosthetic valve or a repair on patients in the young population. We very rarely do a Ross procedure. I am in an adult cardiac center, so we rarely do that. So for patients who have endocarditis, it is usually a prosthetic valve that is utilized, yes.

Back to your first comment where you noticed that most of the time these form quickly and very rapidly and emergently, an area that I would like to look at or do a subanalysis to look at, is to look at the effective orifice area indexed to the body surface area and look at that as far as the initial valve that was placed and how that effective orifice area changed over time and if that was related to an emergent need for a reoperation and a bioprosthetic valve.

Dr Pettersson. Should we be more aggressive with root enlargement?

Dr Milewski. With a small effective orifice I would suggest, yes, do a root enlargement.

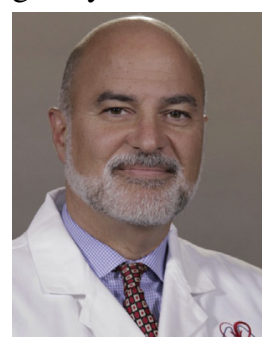

Dr Emile Bacha (New York, NY). Two questions. Can you clarify the endocarditis issue? The patients who came in with endocarditis and then had a bioprosthetic valve implanted were at higher risk for reoperation, correct?

Dr Milewski. Correct, yes.

Dr Bacha. What were the causes of the reoperations? Was it reinfection of the valve? Paravalvular leaks?

Dr Milewski. For the most part it was either reinfection of the valve itself or root abscess.
Dr Bacha. For the second operation?

Dr Milewski. Correct.

Dr Bacha. I understand that it is a different topic, but your findings lead me to believe that bioprosthetic valves are not the right choice in endocarditis.

The other question is the role of transcatheter aortic valve replacement. I ask you to speculate a little bit. So valve-invalve procedures are being done increasingly. In the failed bioprosthetic valve population, where do you see that going and do you think that's going to increase the number of patients who will receive a bioprosthetic valve?

Dr Milewski. Well, obviously valve-in-valve is the thought process for the future, but I think at this point in time, even with the valve-in-valve registry, the follow-up period is short, so we really don't know enough information to make those recommendations to our patients. Obviously, it's a thought process for somebody who is a 6-time redo and in an emergent situation.

To address your first question on placing a bioprosthetic valve, we actually did a study at our institution about 5 or 6 years ago looking at reoperation and types of valves to utilize in patients who had active endocarditis, and we saw no significant difference between the type of valve utilized, whether it was mechanical, bioprosthetic, or a homograft, or stentless.

Unidentified Speaker. I appreciate your presentation and your study. What this all says to me is these solutions are just not good solutions, and I think your last point is the 1 that I would take home and say, we need a better solution, and valve repair techniques may be among those solutions and others to follow. But for us in the audience and especially for the younger folks, I think we just need to work on repair techniques, which may be a technical issue, maybe more so a materials issue in terms of going forward to develop those techniques. But I think that's more where we need to go and I would just emphasize that I agree completely. The fact that valve repair data don't look good today doesn't mean won't in the future.

Dr Milewski. I agree 100\%. In our institution we have seen a significant change in our practices in young patients, especially with the aortic valve population, where 5,6 , or 7 years ago we would have just automatically placed a prosthetic valve, we are now trying more and more to repair those valves.

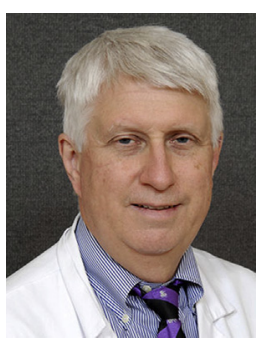

Dr Charles Huddleston (St Louis, $M o$ ). Regarding the notion about what is the best valve for a woman of childbearing age, I have had cardiologists tell me that they can easily handle the anticoagulation without warfarin-aortic valve I'm talking about-and get them through their pregnancy that way. I have concerns that something about pregnancy leads to early degeneration of a bioprosthetic valve. What are your views? 
Dr Milewski. I don't have a lot of experience with pregnant patients with bioprosthetic valves. However, there are several articles that have been published on patients who have mechanical valves who are on anticoagulation therapy who have had multiple miscarriages or congenital problems with the child.
Dr Huddleston. There is no question that warfarin is teratogenic and leads to that, but managed with various heparin products, that's what I am referring to.

Dr Milewski. We don't have a lot of experience, 1 or 2 patients coming through in I think 4 or 5 years who have had pregnancy issues. 